\title{
ESTRATÉGIAS UTILIZADAS POR APRENDIZES DE LÍNGUAS AFINS: A TROCA DE CÓDIGO
}

\section{STRATEGIES EMPLOYED BY LEARNERS OF RELATED LANGUAGES: CODE-SWITCHING}

\section{Roberta Ferroni*}

\section{RESUMO}

Neste artigo analisamos a troca de código, uma estratégia de compensação que consiste na utilização de uma palavra ou frase em L1, L3 ou L4, no interior do enunciado em L2, empregada por aprendizes de italiano LE cuja língua materna é o português brasileiro, durante a realização em dupla de uma tarefa escrita. A pesquisa, que se baseou nos instrumentos propostos pela etnografia, mostra que a troca de código constitui um potencial para o desenvolvimento da interlíngua e para a aquisição/aprendizagem de LE e que tal estratégia, além de compensar eventuais lacunas linguísticas originadas pela falta de recursos adequados para expressar-se em LE, é usada pelos falantes como procedimento típico da conversação bilíngue para facilitar a comunicação.

Palavras-chave: troca de código; estratégias de comunicação; conversação bilíngue.

\section{ABSTRACT}

In this paper we examine code-switching, an achievement strategy consisting in the use of a word or phrase from L1, L3 or L4 within an utterance in L2, as employed by learners of Italian as a foreign language who have Brazilian Portuguese as their mother tongue, while performing a written task in pairs. The research, based on tools provided by an ethnographic approach, shows that code-switching constitutes a potential for developing interlanguage and for the acquisition/learning of a foreign language and that such strategy, in addition to compensating eventual linguistic gaps originated by a lack of proper resources for expression in L2, is used by speakers as a typical procedure in bilingual conversation, in order to facilitate the communication.

Keywords: code-switching; communication strategies; bilingual conversation.

\section{A CLASSE DE LÍNGUA: UM CONTEXTO BILÍNGUE}

A classe de língua é considerada um lugar social singular, onde o bilinguismo ${ }^{1}$ está em fase de construção e onde os interagentes possuem competências assimétricas

\footnotetext{
* USP, São Paulo (SP), Brasil).robertaferroni@hotmail.com

1 Concordamos com Mackey (1976) e Grosjean (1982), que afirmam que o bilinguismo é um fenômeno que não se restringe apenas a algumas comunidades específicas, mas deve ser considerado como um fenômeno individual, presente na maior parte da população do planeta.
} 
entre a língua materna (LM) e a língua-alvo (LS) (PY, 1994). Porquier e Py (2004) frisam que o aprendiz, assim como o falante bilíngue, dispõe de duas competências no interior das duas línguas, as quais são dominadas estruturalmente por uma macrocompetência, cuja função é a de gerar marcas discursivas, caracterizadas pela presença de outra língua dentro do repertório verbal ${ }^{2}$. Essas marcas discursivas contribuem para o desenvolvimento do sistema interlinguístico ${ }^{3}$, são chamadas marcas transcódicas (marques trancodiques) e incluem a troca de código, a tradução literal, o transfer e os estrangeirismos (PORQUIER; PY, 2004).

Neste artigo, vamos abordar especificamente a troca de código ${ }^{4}$, fenômeno natural que não deve ser desestimulado num contexto em que os falantes compartilham línguas diferentes ${ }^{5}$.

Grande parte das pesquisas que estudaram os efeitos produzidos pelo uso da LM na aula de língua estrangeira, presente nas interações entre os aprendizes, examinaram a troca de código ou de um ponto de vista quantitativo e funcional ${ }^{6}$, ou baseando-se nas teorias socioculturais ${ }^{7}$. Os primeiros estudos nos permitiram reconhecer e catalogar as funções desenvolvidas pela $\mathrm{LM}$, ao passo que os estudos de tipo sociocultural provaram que o uso da LM é um importante suporte à disposição do aprendiz, porque é graças ao poder exercido pela linguagem que o indivíduo se constrói cognitivamente. Portanto, o uso da língua materna constitui um meio privilegiado para adquirir competências novas, especialmente quando se prevê a construção de uma língua diferente da própria. É em virtude da referência

2 Por repertório entendemos a totalidade das formas linguísticas utilizadas regularmente no decorrer de interações sociais significativas (GUMPERZ, 1964).

3 A interlíngua é aqui entendida como um sistema linguístico com normas específicas e em transformação contínua, que vai da língua materna à língua-alvo, caracterizado pela presença de material linguístico e uma das duas línguas na outra.

$4 \mathrm{O}$ conceito de uso alternado de duas ou mais línguas dentro do mesmo discurso recebeu diversas denominações. Conforme a perspectiva teórica que se pretende adotar, pode-se falar de code-switching, code-mixing, transfer, code alternation, language alternation e muitos outros. Os estudos sobre a alternância de código no ambiente escolar são de natureza ou gramatical ou interacional. O estudo da alternância de código, segundo a perspectiva gramatical, diz respeito à natureza das restrições morfológicas e sintáticas que condicionam a passagem de uma língua à outra (MYERS -SCOTTON, 1992; POPLACK, 1988). A perspectiva interacional, ao contrário, estuda o sentido e as funções da alternância de código. Os estudos que assinalamos adotam esta última perspectiva, dado que o modelo variacionista de Poplack privilegia análises gramaticais, enquanto nosso interesse dirige-se para o estudo da comunicação na aula de língua estrangeira.

5 De acordo com alguns pesquisadores, ao contrário, o uso da LM na aula de língua estrangeira constitui um obstáculo para a aprendizagem (HOWATT, 1984; WELLS, 1999; TURNBULL, 2002).

6 Cf. Anderson, (2003); Birello, (2005); Cambra; Nussbaum, (1997); Castellotti, (1997); Ferroni, (2010).

7 Cf. Antón; DiCamilla, (1998); Brooks; Donato, (1994); Centeno-Cortés; Jiménez, (2004); Scott; de la Fuente, (2008); Swain, Lapkin, (2000); Villamil; de Guerrero (1996). 
constante à LM que o aprendiz terá condição de planejar e levar a termo diversas atividades, de estabelecer um ambiente de colaboração com os outros participantes, de dominar processos cognitivos indispensáveis para a realização de qualquer tarefa e de expressar sua individualidade.

Outra corrente de pesquisas que pode ajudar na compreensão da importância de que se reveste o uso da LM na fala dos aprendizes é a que estuda as estratégias de comunicação (doravante EC). Dado que comunicar em LE exige grande esforço cognitivo e que os aprendizes de LE possuem uma capacidade de processamento da linguagem diferente daquela que possuem na língua materna (BIALYSTOK, 1990), para superar os problemas comunicativos e melhorar a comunicação, os falantes podem valer-se, em sua interlíngua, de toda uma série de EC, dentre as quais a troca de código, estratégia de compensação (achievement strategy) ${ }^{8}$ que consiste na utilização de uma palavra ou de uma frase em L1 ou L3 no interior do enunciado.

Dado que a conversação que acontece na aula de língua estrangeira oscila entre o exolinguismo e o bilinguismo (PY, 1994), o objetivo deste trabalho será:

- controlar se essa estratégia de comunicação, quando for utilizada por aprendizes cujas línguas são afins e que estão empenhados na execução em dupla de uma tarefa escrita, é utilizada, como prova grande parte da literatura, única e exclusivamente em contextos exolíngues como estratégia de compensação de que os falantes se valem para compensar deficiências devidas a uma competência fraca na $\mathrm{LE}^{9}$, ou se, ao contrário, se manifesta também em contextos bilíngues, a fim de conseguir determinados efeitos e funções comunicativas que a LE não possui ${ }^{10}$;

- averiguar se o uso da troca de código pode ser um potencial para o desenvolvimento da interlíngua e, portanto, para a aquisição/aprendizagem da LE.

Para a análise do corpus empregaremos os instrumentos disponibilizados pela análise da conversação, disciplina que valoriza principalmente os aspectos micro e

8 Grande parte da literatura divide as estratégias em duas áreas: estratégias de compensação (achievement strategy) e estratégias de evitamento (reduction strategy). As estratégias de evitamento destinam-se a reduzir as ambições comunicativas à medida dos recursos disponíveis, a fim de o aluno ser bem-sucedido em um âmbito restrito: abandono da mensagem, troca de assunto, substituição do sentido. As estratégias de compensação destinam-se a melhorar o nível da comunicação. São exemplos de estratégias de compensação: a troca de código, a tradução literal, o transfer e os estrangeirismos (QCER, 2002).

9 Veja-se Tarone (1981), Faerch e Kasper (1983), Bialystok (1983), Lombardo (1995) e Dörnyei e Kormos (1998).

10 Lüdi e Py (2003) distinguem três tipos de conversação: a) a conversação endolinguística, que é um modelo idealizado de conversação no qual não há divergência de línguas entre os interlocutores; b) a conversação bilíngue, que representa um modelo no qual a interação verbal é caracterizada pelo uso simultâneo das duas línguas; c) a conversação exolinguística que é caracterizada pela divergência entre o repertório linguístico dos participantes. 
que, em lugar de formular regras de valor absoluto, procura encontrar na interação regularidades estruturais que orientam o trabalho de interpretação e de construção conjunta do sentido.

Para classificar e analisar essa estratégia de comunicação, presente nas interações de aprendizes cuja LM é afim à LE, valemo-nos da taxonomia proposta por Dörnyei e Kormos (1998), ${ }^{11}$ que tem a vantagem de considerar, além dos processos cognitivos, a natureza interativa da comunicação e a negociação do sentido ${ }^{12}$.

\section{0 CONTEXTO}

Os dados que vamos analisar foram obtidos mediante a observação de uma classe composta por 6 estudantes de língua materna português-brasileiro, de nível B2, inscritos no curso de Língua e Literatura Italiana de uma Universidade do Estado de São Paulo. Preferimos observar um grupo de nível avançado porque, como confirmam os trabalhos de Bialystok (1990), o nível linguístico dos aprendizes pode influenciar o uso de estratégias de comunicação, ou seja, quanto maior for a competência linguística, maior será o uso de estratégias de comunicação. Os dados que analisamos referem-se exclusivamente às interações entre alunos e não consideram as interações entre o grupo classe e o professor. As 15 horas de gravação foram obtidas enquanto os estudantes estavam realizando, em dupla, tarefas escritas, atividades que se fundamentam na convicção de que somente por meio da interação é possível adquirir a LE, porque a produção permite observar os recursos utilizados para expressar com sucesso aquilo que se pretende dizer (SWAIN, 1985), ao passo que a interação e a negociação melhoram a compreensão (LONG, 1996).

\section{METODOLOGIA}

Uma das metodologias amplamente utilizadas, no âmbito da aquisição, para o estudo das EC é a observação de um contexto fictício como o laboratório, no qual

11 Ver Tabela 1.

12 Os dados que vamos apresentar são fruto de uma pesquisa de doutorado, ainda em desenvolvimento, cujo objetivo é a análise das estratégias baseadas na LM, presentes na fala dos aprendizes cujas línguas são afins. 
se pede aos aprendizes que desenvolvam algumas atividades, como descrever uma imagem (BIALYSTOC; FROHLICH, 1980; VÁRADI, 1980), traduzir (GALVAN, CAMPBELL, 1979), completar frases (BLUM-KULKA; LEVESTON, 1983), conversar (HAASTRUP; PHILLIPSON, 1983). De acordo com alguns autores (BIALYSTOK $;$ SWAIN, 1978), o contexto natural, por sua complexidade, poderia condicionar o uso estratégico da língua, tornando difícil a interpretação, ao passo que o laboratório garante que variáveis estranhas ao contexto possam ser mantidas sob controle com mais eficácia.

Esta pesquisa, ao contrário, valeu-se de instrumento de investigação da etnografia, dado que um dos valores agregados de uma pesquisa etnográfica detalhista é a dimensão qualitativa em lugar da quantitativa, possível graças à observação estudada. Com efeito, é por meio da observação que o pesquisador poderá perceber, em profundidade, os diferentes pontos de vista da realidade dos participantes e o sentido que eles vão atribuir aos acontecimentos, às interações e às consequências.

A técnica utilizada para a coleta dos dados baseia-se na observação da classe, na gravação e na posterior transcrição.

As gravações foram feitas por meio de um gravador, instrumento que permite manter o distanciamento necessário dos dados levantados e também permite perceber aspectos que poderiam ser ignorados por um observador acostumado ao contexto da aula (VAN LIER, 1988; NUNAN, 1992).

A presença do gravador e do pesquisador no setting é uma das dificuldades principais quando se pretende obter dados que deveriam ser "naturais" e "espontâneos". É o "paradoxo do observador", já comentado por Labov (1970, p. 209, tradução nossa). Como comenta Blum Kulka (1997), quando se estuda a interação social, a observação objetiva é inatingível: a escolha do pesquisador não é entre intervir ou não intervir na situação estudada, mas, simplesmente, entre maneiras mais ou menos invasivas de intervir. Toda pesquisa que se propõe a estudar a realidade social em profundidade, de um ponto de vista êmico, nunca poderá ser considerada plenamente objetiva, mas deverá ser vista sempre como um complexo interplay entre a realidade observada e a visão de mundo de quem a observa. A presença do observador não cria um contexto falso, mas cria simplesmente um contexto novo, que deve ser estudado como tal, com sua rede peculiar de relações entre o pesquisador e os participantes.

As etapas da transcrição dos dados foram as seguintes: num primeiro momento, foram ouvidas todas as gravações; a seguir, foram selecionados os segmentos em que era utilizada a LM. Em seguida, o segmento selecionado era transcrito. As 
normas que utilizamos para transcrever os dados são aquelas propostas por Van Lier (1988), com algumas adaptações ${ }^{13}$.

O problema maior que tivemos de enfrentar durante a fase de transcrição foi a compreensão de tudo aquilo que os estudantes diziam no decorrer das interações. As falas, em alguns casos, eram quase incompreensíveis seja por causa dos barulhos e da sobreposição das vozes da dupla e dos outros colegas, seja porque os alunos falavam em voz baixa. Por causa disso, o corpus apresenta enunciados incompreensíveis, indicados entre parênteses ((inc)).

Para facilitar a legibilidade das transcrições, adotamos o sistema jeffersoniano descrito por Sacks, Schegloff e Jefferson (1974), que apresenta os turnos seguindo o formato típico dos roteiros teatrais:

\section{A ANÁLISE}

A troca de código, assim como todas as outras estratégias baseadas na L1, pelo simples fato de ser uma estratégia de compensação (acbievement strategy), tipo de estratégia que exige do aprendiz a tentativa de querer comunicar algo, mesmo sabendo que não dispõe dos recursos linguísticos adequados para isso, apresenta, em comparação com as estratégias de evitamento (reduction strategy), um potencial maior para a aprendizagem, porque induz o falante a formular hipóteses e a enfrentar o problema, mesmo correndo o risco de não ser bem-sucedido $(\mathrm{FAERCH} ; \mathrm{KASPER}$, 1983). A troca de código consiste na utilização de uma palavra ou de uma frase em L1 ou L3, no interior do enunciado. Lançando mão da troca de código, o aprendiz utiliza ilhas de segurança para expressar um conceito e enfrentar uma situação nova, desconhecida.

De um ponto de vista quantitativo, são frequentes os momentos em que os aprendizes se serviram da troca de código. Além disso, é preciso dizer que o uso da LM não ocorre nem em nível de frase nem em nível de discurso, mas somente para substituir palavras isoladas das quais o aluno desconhece o correspondente em italiano. Vejamos o exemplo a seguir.

13 As normas que utilizamos para transcrever: P professor; Ad, An, F, L, M, Pa iniciais utilizadas para

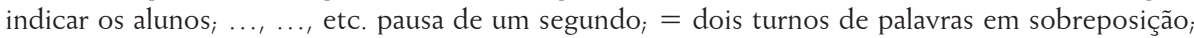
((inc)), ((risos)) o parêntese duplo indica uma parte da conversação incompreensível ou comentários sobre a transcrição, como risos etc.; no- um hífen indica uma interrupção brusca; eh::: os dois pontos repetidos por três vezes seguidas indicam um som prolongado; ? entoação ascendente ! $^{\prime}$ entoação descendente; texto mudança de código; (texto) TL tradução literal; (texto) TR transferência; (texto); ES estrangeirismo. 


\section{EXEMPLO 1}

Em dupla, devem responder a algumas perguntas sobre o vídeo.

An: è una immagine delle solennità civili è una parte di roma è un:::è un::: come si dice bairro bairro

Ad: bairro quartiere

Nessa sequência, os estudantes estão respondendo, em duplas, a perguntas sobre um vídeo que acabaram de assistir. Dado que An não sabe como se diz "quartiere", num primeiro momento, tenta ganhar tempo alongando e autorrepetindo a cadeia sonora "è un:::è un:::"; em seguida, utiliza um pedido para pedir ajuda ao colega e o faz utilizando o termo em LM "come si dice bairro", Ad intervém prontamente e sugere o termo em italiano "quartiere". Exemplos como esses são numerosíssimos e apresentam características que vamos comentar a seguir. Em primeiro lugar, as trocas de código estão sempre circunscritas a palavras isoladas. Criam um contexto favorável para a heterorreparação de tipo atenuado ${ }^{14}$ e são quase sempre seguidas pela reparação do interlocutor B, que dá o termo em italiano, e pela autocorreção no terceiro turno de A.

A sequência em que a troca aparece é sempre precedida por hesitações, pausas e repetições, que permitem que quem fala mantenha aberta a conversação e ganhe tempo, antes de terminar a mensagem. A solução do problema acontece segundo uma modalidade cooperativa em que os falantes interagem e negociam o sentido junto com a produção de diversos turnos de palavra para procurar a palavra correta, modalidade que parece ser uma das mais produtivas para fins de aprendizagem (GASS, MACKEY; PICA, 1998; LONG, 1983; SWAIN; LAPKIN, 1998). Dessa forma, graças à condição a priori igualitária, instaura-se uma ordem interacional na qual todos os participantes usufruem os mesmos direitos e os mesmos deveres conversacionais ${ }^{15}$, tanto isso é verdade que a assunção do turno acontece por meio de autosseleção mais do que por meio de heterosseleção ${ }^{16}$. Não

14 As heterocorreções empregadas nas conversações entre pares são atenuadas em comparação com aquelas em que os falantes têm potencialidades conversacionais desiguais, como nas interações entre professor e estudantes, porque a correção não é assertiva, mas é proposta, podendo ser aceita ou recusada (SCHEGLOFF; JEFFERSON; SACKS, 1977).

$15 \mathrm{Na}$ interação entre professor e alunos, por causa da assimetria dos papéis, ocorre com frequência que o professor interrompa os estudantes e se aproprie da palavra, acabando com o princípio conversacional da cooperação.

16 Estudando a interação na sala de aula, Van Lier (1988) e Orletti (2000) destacam a tendência dos participantes a adotar, na troca de turnos, a técnica da heterosseleção, de acordo com a qual quem está falando, nesse caso, o professor, escolhe o falante seguinte. A autosseleção, técnica de assunção de turno que, ao contrário, consiste na autoindicação, é típica das atividades em grupo (CAMBRA, 2003). Os primeiros que falaram de auto e heterosseleção foram Sacks, Schegloff e Jefferson (1974). 
haverá nem interlocutores excessivamente silenciosos, nem sobreposições, nem "incontinência verbal" (CAMBRA, p. 76, tradução nossa).

Há casos em que o falante não sente necessidade do feedback do colega e faz tudo sozinho, como se observa na sequência 2:

\section{EXEMPLO 2}

L e Pa estão escrevendo o texto juntos.

L: ha cominciato a camminare::: prima di arrivare::: al gabinetto perché qua dice che lei era al gabinetto

Pa: e se mettiamo... ha messo la mano destra nella tasca e ha preso un pacchetto di sigaretto::: sigaretti::: sigarette mentre nazarena e michelina la inseguivano.... la inseguivano eh::: continuavano a (blasfemare) TL due punti no? ((escreve no papel o que disse)) mentre nazarena e michelina la inseguivano::: e::: continuavano a (blasfemare) TL (diasfemare) ES no?

L: io credo di sì

Pa: (blasfemare) TL (diasfemare?) ES biasimare? cos'è biasimare quando si dice una grossa parola ((inc)) come si dice blasfêmia?... bestemmiare

Nesse trecho, Pa está escrevendo um texto junto com um colega e não lembra como se diz "bestemmiare" (blasfemar). Antes de chegar à solução, emprega várias estratégias. Inicialmente, cria um termo novo "diasfemare"; em seguida, por não ter certeza de que esse termo seja correto, ganha tempo e repete "biasimare" por duas vezes (autorrepetição). Depois, na tentativa de ser entendido pelo colega, utiliza uma circunlocução "quando si dice una grossa palavra" e, finalmente, pede ajuda diretamente ao colega "come si dice blasfêmia?", por meio de uma pergunta na qual aparece a LM, mas somente após ele ter gasto todas as suas munições na LE. Só nesse momento, Pa encontra o termo que estava procurando "bestemmiare". $\mathrm{O}$ que mais impressiona nesse exemplo são as estratégias variadas de que o falante lança mão para encontrar a palavra em LE. Além disso, a troca de código, como no exemplo anterior, aqui também aparece somente no fim. Antes de apelar para a LM o aprendiz, por meio de uma atividade discursiva criadora, vale-se de diversos meios para se fazer entender.

Em certos casos, o aprendiz, além de apelar para a LM, utiliza também outras línguas conhecidas. Veja-se, a esse respeito, o recorte seguinte: 


\section{EXEMPLO 3}

Após a primeira exibição do vídeo, devem conversar sobre aquilo que entenderam

Pa: non so per me sembra che questo::: come si dice. bastidores come si dice making loch di un film o documentario sull'epoca

C: è può darsi

$\mathrm{Pa}$, que não sabe como se diz em italiano "dietro le quinte", antes ganha tempo alongando o som "questo:::"; depois, diz em português "bastidores" e, finalmente, em inglês making loch. Apesar dessas tentativas, a sequência fica sem solução, porque também $C$ não conhece o termo. Nesse sentido, cabe dizer que a passagem de uma língua para outra, seja ela a L1 ou L3 ou L4, contribui para a realização de uma competência plurilíngue e pluricultural ${ }^{17}$, competência que deverá ser valorizada na aula de língua estrangeira, visto que, atualmente, a finalidade da educação linguística não consiste mais na aquisição do domínio de uma, duas ou três línguas estrangeiras de maneira isolada, mas visa estimular o desenvolvimento de um repertório linguístico no qual todas as capacidades e habilidades compartilham um espaço comum (QCER, 2002). A abordagem plurilíngue prevista pelo Quadro, que aqui é compartilhada, fundamenta-se, em síntese, na convicção de que os conhecimentos e as experiências linguísticas de cada indivíduo colaboram, reciprocamente, para a formação da assim chamada competência comunicativa.

Constituem uma categoria à parte, que denominamos trocas de código lapsus e que pertencem, de acordo com a classificação de Dörnyei e Kormos (1998), aos mecanismos utilizados pelo falante para resolver problemas presentes no próprio output (problem-solving mechanisms), ou seja, todas as trocas de código produzidas acidentalmente. Embora não sejam significativas numericamente, essas trocas merecem ser mencionadas, dado que, diferentemente das anteriores, são sequências que contêm, como no exemplo 4, a LM, cujo uso, porém, é logo interrompido por meio de uma reparação:

$17 \mathrm{O}$ conceito de competência plurilíngue e pluricultural que pretendemos enfatizar aqui é aquele introduzido por Coste, Moore e Zarate (1997), e adotado, em 2001, pelo Conselho da Europa no QCER. Ele designa o conjunto de conhecimentos e capacidades que permitem mobilizar, de acordo com a função e as circunstâncias, todo o repertório plurilíngue de que cada falante dispõe. Ser plurilíngue significa saber passar de uma língua a outra, de acordo com as necessidades e as situações, mesmo tendo uma competência muito assimétrica. 


\section{EXEMPLO 4}

Grupo Ad e Pa: leram a resenha e devem responder juntos às perguntas.

Ad: qui parla di costantino piccolo è anche qui costantino piccolo qui costantino adulto e qui eh::: fal- parla proprio del film

Nesse caso, diferentemente dos outros exemplos, a LM não está sendo usada intencionalmente pelo falante, porque ele conhece o termo em italiano. Na realidade, trata-se de um lapsus, seguido, na mesma sequência, por uma autorreparação. O que torna possível esse processo é o monitor que, no momento em que percebe a presença do erro (nesse caso, a troca de código), manda um sinal de alerta ao conceitualizador que, imediatamente, corrige o erro de produção (LEVELT, 1989).

Finalmente, outra subcategoria que aparece no corpus é constituída pela troca-tradução, estratégia típica dos contextos monolíngues. Diferentemente das sequências analisadas até aqui, que pertencem ao contexto exolinguístico, por serem utilizadas pelos interlocutores para suprir lacunas linguísticas na LE, o falante que se serve da LM, como no caso dos exemplos apresentados em seguida, não faz isso porque não possui os recursos linguísticos adequados para expressar-se em LE, mas para facilitar a compreensão do colega e para poupar tempo. Em outras palavras, trata-se de um procedimento de heterofacilitação, típico da conversação bilíngue, que ajuda a tornar a comunicação mais fluente ${ }^{18}$ e cujo objetivo é a negociação do sentido. Essa estratégia, que repete sempre o mesmo esquema - termo em LE seguido pela tradução em LM - aparece após um pedido direto de ajuda por parte do interlocutor, que pede ajuda por não conhecer o sentido de um termo desconhecido em LE. São sequências características da interação entre pares e são raras nas interações assimétricas devido ao receio dos alunos de serem julgados negativamente pelo professor. Veja-se o exemplo seguinte, em que, para responder à pergunta do colega "che cos'è scema?", em lugar de usar uma circunlocução que exigiria mais tempo, L, após uma rápida hesitação, prefere, a fim de manter a comunicação aberta e mais fluente, empregar a tradução "scema...bobo":

\section{EXEMPLO 5}

L e F devem formular hipóteses sobre o conteúdo do diário por meio das imagens e dos trechos extraídos do texto.

18 Denominamos fluência a capacidade do sujeito de articular e sustentar um discurso e de fazer frente a uma situação. 


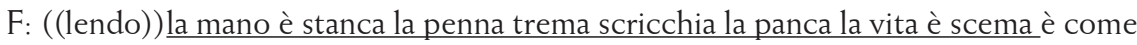
un poemetto

che cosa è scricchia?

L: scricchia non lo so

F: neanche la panca

L: la panca sarebbe come il panchino?

F: mmm:: non lo so e scema che cos'è scema?

L: scema ... bobo ((em voz baixa))

A LM pode aparecer quando se deseja obter uma confirmação sem perder tempo; ela se apresenta como um pedido direto dirigido ao interlocutor:

\section{EXEMPLO 6}

Procuram a palavra no dicionário.

Pa: ci sono ((escrevendo)) eh::: elencare c'è elencare?

Ad: ((consultando o dicionário)) enu- enumerare annoverare sciorinare

Pa: nossa sciorinare

Ad: enunciare anche enumerare

$\mathrm{Pa}$ : forse enumerare oh

Ad: ele- elen

$\mathrm{Pa}$ : elencare sarebbe listar no? elenco?

Nessa sequência, Pa e Ad estão escrevendo um texto juntos e consultam o dicionário para confirmar se existe ou não a palavra "elencare". Dado que encontram vários sinônimos, Pa manifesta sua perplexidade e pede a ajuda do colega por meio de um pedido direto, que contém uma troca-tradução "elencare sarebbe listar no?".

Além disso, a troca-tradução pode ser útil quando se quer prevenir uma dificuldade previsível do colega:

\section{EXEMPLO 7}

Respondendo às perguntas.

L: colocaria l'abbigliamento::: roupa

F: sì abiglia::: ((escrevendo)) come si scrive?

L: abbiglia (gli) TF

F: ah 
O uso dessa estratégia é particularmente importante na aula de língua estrangeira, em primeiro lugar, porque nos permite dizer que a LM não aparece exclusivamente quando há problemas de ordem linguística, mas que, em situações em que os falantes utilizam a mesma língua, ela pode ser empregada para tornar a comunicação mais eficaz e para negociar o sentido (GASS, 2005; SWAIN, LAPKIN, 1998). Esse uso da LM, em lugar de ser interpretado como uma deficiência linguística, deve ser visto como a manifestação da capacidade que os sujeitos bilíngues in fieri possuem de estabelecer relações recíprocas entre as línguas que compõem seu repertório, para a obtenção de determinados efeitos.

Além do mais, será esperada especialmente nos contextos de aprendizagem que promovem a negociação e a interação, visto que a função desses contextos é tornar compreensível o input e, portanto, promover novas formas de aprendizagem. Ao contrário das aulas tradicionais, baseadas nas trocas entre professor e aluno, que podem inibir a aquisição da LE, estamos diante de uma interação cooperativa, cuja finalidade é a negociação do sentido, que será capaz de promover o desenvolvimento da competência conversacional em LE.

\section{À GUISA DE CONCLUSÃO}

Da análise das sequências que compõem o corpus emerge que a troca de código é uma das estratégias baseadas na L1 mais empregadas pelos falantes, durante a realização de atividades em duplas. que têm a tarefa de produzir, em conjunto, um texto escrito. Antes de recorrer à LM, o aprendiz deixa uma série de sinais estratégicos como hesitações, pausas salientes, que interrompem a continuidade fônica, alongamentos do som, repetições e risos, indícios que, em nossa opinião, além de confirmar que o falante tem consciência de estar enfrentando um problema na execução da tarefa, manifestam que quem fala deseja permanecer na língua-alvo. $\mathrm{O}$ falante que se serve da LM, provavelmente devido à presença do gravador que força os estudantes a utilizarem a LE (NUSSBAUM, 1999), recorre a ela contra vontade, tanto é verdade que, antes de fazer isso, esforça-se e tenta ganhar tempo. Vimos que o uso da LM não se verifica em nível de frase ou de discurso, mas, na maioria das vezes, em nível de palavras isoladas; isso é compreensível dado que se trata de aprendizes de línguas afins, dotados de uma boa competência na língua-alvo. Uma vez que o falante resolve recorrer à LM, sua escolha apresenta consequências. Com muita frequência intervêm mecanismos que levam os participantes a produzirem 
sequências laterais ${ }^{19}$ de natureza metalinguística que, embora não apresentem uma terminologia específica, visto que a natureza da tarefa é dirigir os aprendizes para a comunicação ${ }^{20}$, acionam uma série de "Séquences Potentiellement Acquisitionnelles" (DE PIETRO; MATTHEY; PY, 1989), compostas por estratégias como pedidos diretos, circunlocuções, tradução literal, auto e heterocorreções no intuito de substituir o termo em LM. Nesse sentido, podemos afirmar que a troca de código constitui um potencial para a aprendizagem, dado que induz o aprendiz a formular hipóteses, a produzir e a enfrentar o problema, mesmo correndo o risco de não ser bemsucedido (QCER, 2002). Com efeito, a produção pode estimular o desenvolvimento da LE porque obriga o aprendiz a prestar atenção nos recursos expressivos de que necessita para transmitir, com sucesso, o que pretende dizer (SWAIN, 1985).

Por outro lado, são raras as vezes em que o uso da LM passa despercebido e acaba não sendo corrigido pelo iniciador ou por seu interlocutor. Na maioria dos casos, é acompanhado por um feedback que, por sua vez, origina negociações posteriores, reformulações, modificações, auto e heterocorreções, todas atividades metalinguísticas particularmente favoráveis à aprendizagem da LE.

Com relação às taxonomias elaboradas até hoje, consideramos necessário apontar, além da citada troca de código, também uma série de subcategorias, que são: as trocas lapsus (trocas em que a LM não é utilizada intencionalmente pelo falante, mas por distração) e as trocas de tradução. É verdade que a maioria das sequências que contém a troca de código é típica do contexto exolinguístico, porque essas sequências são utilizadas pelos interlocutores para suprirem lacunas linguísticas na LE; mas há, também, uma categoria específica formada pelas trocas de tradução, empregadas para facilitar a compreensão do colega e para poupar tempo. Trata-se,

19 De acordo com as áreas de estudo, fala-se em metalinguagem, metadiscurso, formulações, práticas de glosa, sequências laterais, atos de reformulação, reflexividade, etc. As disciplinas principais que se ocuparam da "metacomunicação" e contribuíram para sua evolução são: a filosofia da linguagem, a psicologia cognitiva, a linguística, a psicologia social, a análise da conversação e a sociolinguística. Nesse contexto, vamos utilizar indistintamente os termos atividades metalinguísticas e sequências laterais para indicar sequências subsidiárias e não subsidiárias que competem com a sequência principal, nas quais se desencadeia uma sequência dentro da outra (ORLETTI, 2000; VAN LIER, 1988; VION, 1992), com função esclarecedora. Esses tipos de intervenção provocam o bloqueio imediato do desenvolvimento temático em curso. Encontram-se não somente na interação verbal na aula, como também na conversação natural (SCHEGLOFF, 1972). Em contextos exolíngues, são sequências que favorecem a aquisição, porque induzem os falantes a procurar os recursos adequados para se expressarem (DE PIETRO; MATTHEY; PY, 1989).

20 Por causa da assimetria presente no repertório linguístico originada pelo exolinguismo, os interactantes deverão exercer um controle cuidadoso na comunicação, para gerenciar problemas de natureza formal e comunicacional. Essa vigilância dúplice, denominada bifocalização (BANGE, 1992), irá produzir, nas trocas entre professor e estudantes, interações cheias de referências gramaticais que provocam um bloqueio momentâneo da comunicação. 
em síntese, de um procedimento de heterofacilitação, cujo objetivo é a negociação do sentido, procedimento característico da conversação bilíngue que serve para tornar a comunicação mais fluente.

Se, como resulta nos exemplos, a troca de código ou a troca de tradução são empregadas pelos aprendizes para tornar o input compreensível, então, o uso dessas estratégias pode constituir um potencial para o desenvolvimento da interlíngua e, portanto, para a aquisição/aprendizagem da LE, dado que aparecem em sequências em que os aprendizes negociam o sentido e tentam produzir um output mais correto (GASS; MACKEY; PICA, 1998; LONG, 1983; PICA, 1987). Os casos em que a LM não é resolvida ou não é observada são poucos. A presença da LM, devido à sua "diversidade", graças também a sinais prosódicos (pausas, hesitações, interrupções, risos, etc.), desencadeia uma série de processos de auto e heterocorreção que induzem os falantes a produzirem um feedback mais correto. Portanto, a troca de código presente nesse contexto, quando empregada como estratégia de comunicação, além de representar uma solução imediata para fins de comunicação, constitui um potencial para o desenvolvimento da interlíngua, dado que induz os aprendizes a modificar e a reorganizar seu próprio output, para transmitirem com sucesso o que desejam dizer (SWAIN, 2005).

$\mathrm{Se}$, até hoje, a troca de código foi classificada, sem distinções significativas, como estratégia de compensação, utilizada pelos falantes para enfrentar problemas de comunicação em LE, em termos práticos, o aprendiz lançaria mão de sua própria LM para compensar deficiências de tipo gramatical, fonológico, lexical e comunicacional, devidas à competência fraca em L2. Observando os dados de que dispomos, graças à análise do contexto que permitiu destacar a dimensão comunicativa em lugar de examinar somente os fenômenos linguísticos, com frequência extraídos de situações artificiais, concluímos que o uso dessa estratégia não visa somente à superação de determinados obstáculos linguísticos. A interlíngua dos aprendizes que observamos é caracterizada por um espaço dinâmico, híbrido e em construção, um espaço disputado pelo exolinguismo, que abrange as estratégias que servem para compensar as lacunas linguísticas decorrentes da falta de recursos adequados para a expressão em LE, e o bilinguismo, caracterizado por estratégias discursivas e por estratégias meramente expressivas, realizadas mediante a troca de código, cujo objetivo pode ser facilitar a compreensão do colega ou poupar tempo. Trata-se, portanto, de um procedimento de heterofacilitação, que visa à negociação do sentido e que pode aparecer também na conversação bilíngue para tornar mais fluente a comunicação. Posto que o monolinguismo não existe e que todos os falantes dispõem de múltiplos recursos que se integram para a construção 
de seu patrimônio linguístico (CASTELLOTTI, 2006), é desejável que essa riqueza de repertório seja valorizada também na aula de língua estrangeira.

\section{REFERÊNCIAS BIBLIOGRÁFICAS}

ANTÓN, M.; DiCAMILLA, F. (1998). Socio-cognitive functions of L1 collaborative interactions in the L2 classroom. Canadian Modern Language Review. v. 54, $\mathrm{n}^{\circ} 3$, pp. 314-342.

ANDERSON, L. (2003). Processi di commutazione di codice nella classe di lingue. In: CILIBERTI, A.; PUGLIESE, R.; ANDERSON, L. (Org.). Le lingue in classe: discorso, apprendimento, socializzazione. Roma: Carocci, pp. 75-91.

BANGE, P. (1992). A propos de la communication et de l'apprentissage de L2 notamment dans ses formes institutionnelles. AILE. v. 1, n 1, pp. 53-85.

BIALYSTOK, E. (1983). Some factors in the selection and implementation of communication strategies. In: FAERCH, C; KASPER, G. (Org.). Strategies in interlanguage communication. London: Longman, pp. 100-118.

(1990).Communication strategies: a psychological analysis of second-language use. Oxford: Basil Blackwell.

BIALYSTOK, E.; FROHLICH, M. (1980). Oral communication strategies for lexical difficulties. Interlanguage Studies Bullettin. v. 5, n 1, pp. 3-30.

BIALYSTOK, E.; SWAIN, M. (1978). Methodological approaches to research in second language learning. McGill Journal of Education. v. 8, n 1, pp. 137-144.

BIRELLO, M. (2005). Las alternancia de lenguas en la clase de italiano lengua estranjera. Su uso en las interacciones en subgrupos de alumnos adultos en Cataluña. Tese de Doutorado em Didàctica de la Llengua i de la Literatura. Departament de Didàctica de la LLengua i la Literatura, Universitat de Barcelona, Barcelona.

BLUM-KULKA, S. (1997). Dinner talk: cultural pattern of sociability and socialization in family discourse. New Jersey: Lawrence Erlbaum Associates Publishers.

BLUM KULKA, S.; LEVENSTON, E.A. (1983). Universal of lexical simplification. In: Faerch, C; Kasper, G. (Org.). Strategies in interlanguage communication. London: Longman, pp. 119-139.

BROOKS, F.B.; DONATO, R. (1994). Vygotskyan approaches to understanding foreign language learner discourse during communicative tasks. Applied Linguistics. v. 77, $\mathrm{n}^{\circ} 2$, pp. 262-274.

CAMBRA, M. (2003). Une approche ethnograpbique de la classe de langue. Paris: Didier.

CAMBRA, M.; NUSSBAUM, L. (1997). Gestion des langues en classe de LE. Le poids des représentations de l'enseignant. Études de Linguistique Appliquée. v. 108, n 1, pp. $423-432$. 
CASTELLOTTI, V. (1997). Langue étrangère et français en milieu scolaire: didactiser l'alternance? Études de Linguistique Appliquée. v. 108, n 1, pp. 401-410.

(2006). Pratiques réflexives en contexte plurilingue: le porfolio européen des langues puor le collège. In: MOLINIE, M.; BISHOP, M.F. (Org.). Autobiograpbie et réflexivité. Paris: Université de Cergy-Pontoise, pp. 69- 82.

CENTENO-CORTÉS, B.; JIMÉNEZ JIMÉNEZ, A. F. (2004). Problem-solving tasks in a foreign language: the importance of the $\mathrm{L} 1$ in private verbal thinking. International Journal of Applied Linguistics. v. 14, $\mathrm{n}^{\circ}$ 1, pp. 7-35.

COSTE, D.; MOORE, D.; ZARATE, G. (1997). Compétence plurilingue et pluriculturelle. Vers un Cadre Européen Commun de reference pour l'einseignement et l'apprentissage des langues vivantes: etudes préparatoires. Strasbourg: Editions du Conseil de L’Europe.

DE PIETRO, J.; MATTHEY, M.; PY, B. (1989).Acquisition te contrat didatique: les séquences potentiellement acquisitionnelles de la conversation exolingue. In: Actes du 3e Colloque régional de linguistique. Strasbourg: Université des Sciences Humaines et Université Louis-Pasteur, pp. 99-124.

DÖRNYEI, Z.; KORMOS, J. (1998). Problem-solving mechanism in L2 communication. Studies in Second Language Acquisition. v. 20, n 1, pp. 349-385.

FAERCH, C; KASPER, G. (1983). Strategies in interlanguage communication. London: Longman. FERRONI, R. (2010). A comutação de código na sala de língua. Humanitas: São Paulo.

GALVAN, J.; CAMPBELL, (1979). R. An examination of the communication strategies of two children in the Culver City Spanish immersion program. In: ANDERSON, R. (Org.). The acquisition and use of spanish and english as first and second languages. Washington: Tesol, pp. 133-150.

GASS. S. (2005). Input and interaction. In: DOUGHTY, C. J.; LONG, M. L. (Org.). The bandbook of second language acquisition. Oxford: Blackwell Publishing, pp. 224-255.

GASS, S.; MACKEY, A.; PICA, T. (1998). The role of input interaction in second language acquisition: introduction to the special issue. The Modern Language Journal. v. 82, $\mathrm{n}^{\circ} 3$, pp. 299-307.

GROSJEAN, P. (1982). Life with two languages: an introduction to bilingualism. Cambridge: Harvard University Press.

GUMPERZ, J. (1964). Linguistic and social interaction in two communities. American Antbropologist. v. 66, n 6, pp. 137-153.

HAASTRUP, P.; PHILIPSON, R. (1983). Achievement strategies in learner/native speaker interaction. In: FAERCH, C; KASPER, G. (Org.). Strategies in interlanguage communication. London: Longman, pp. 140-158.

LABOV, W. (1970). The study of language in its social context. Studium Generale. v. 23, $\mathrm{n}^{\circ}$ 1, pp. 30-87.

LEVELT, W. J.M. (1989). Speaking: from intention to articulation. Cambridge: MIT Press.

LOMBARDO, L. (1995). Competenza strategica e strategie comunicative nell'interazione dello studente. In: PIAZZA, R. (Org.). Dietro il parlato. Conversazione e interazione verbale nella classe di lingua. Firenze: La Nuova Italia, pp. 187- 216. 
LONG, M. H. (1996). The role of the linguistic environment in second language acquisition. In: RITCHIE, W. C.; BHATIA, T. K. (Org.). Handbook of second language acquisition. San Diego: Academic Press, pp. 413-468.

LONG, M. H. (1983). Does second language instruction make a difference? A review of the research. Tesol Quarterly. v.17, n³, pp. 359-82.

MACKEY, W.F. (1976). Bilinguisme et contact de langues. Paris: Klincksieck.

MYERS SCOTTON, C. (1992). Duelling languages: grammatical structure in codeswitching. Oxford: Clarendon Press.

NUNAN, D. (1992). Research methods in language learning. New York: Cambridge University Press.

NUSSBAUM, L. (1999). Émergence de la conscience langagière en travail de groupe entre apprenants de langue ètrangère. Langages. v. 134, ${ }^{\circ} 1$, pp. 35-50.

ORLETTI F. (2000). La conversazione diseguale. Potere e interazione. Roma: Carocci.

PICA, T. (1987). Second-language acquisition, social interaction, and the classroom. Applied Linguistics. v. 8, n 1 , pp. 3-21.

POPLACK, S. (1988). Contrasting patterns of code switching in two communities. In: HELLER, M. (Org.). Codeswitching. Anthropological and sociolinguistic perspectives. Berlin: Mouton de Gruyter, pp. 243-261.

PORQUIER, R.; PY, B. (2004). Apprentissage d'une langue étrangère: contexts et discours. Paris: Didier.

PY, B. (1994). Place des approches interactionnistes dans l'étude des situations de contacts et d'acquisition. In: VÉRONIQUE, D. (Org.). Créolisation et acquisition des langues. Aix en Provence: Publications des Universités de Provence, pp. 136-147.

QUADRO comune europeo di riferimento per le lingue: apprendimento insegnamento valutazione. Firenze: La Nuova Italia-Oxford. (2002). 263 p.

SACKS, H, SCHEGLOFF, E.; JEFFERSON, G. (1974). A simplest systematic for the organization of turn-taking in conversation. Language. v. 50, n 4, pp. 696-735.

SCHEGLOFF, E. (1972). Sequencing in conversational openings. In: Gumperz, J.; Hymes, D. (Org.). Directions in sociolinguistics: the ethnograpby of communication. New York: Holt, pp. 346-379.

SCHEGLOFF, E.j JEFFERSON, G.; SACKS, H. (1977). The preference for self-correction in the organization of repair in conversation. Language. v. 53, $\mathrm{n}^{\circ} 2$, pp.361-382.

SCOTT, V. M.; de la FUENTE, M. J. (2008). What's the problem? L2 learners' use of the L1 during consciousness-raising, form-focused tasks. The Modern Language Journal. v. $92, \mathrm{n}^{\circ} 1$, pp. 100-113.

SWAIN, M. (1985). Communicative competence: some roles of comprehensible input and comprehensible output in its development. In: GASS, S. M.; MADDEN, C. G. (Org.). Input in second language acquisition. Mahwah, NJ: Lawrence Erlbaum, pp. 235 253. 
SWAIN, M.; LAPKIN, S. (2000). Task-based second language learning: the use of the first language. Language Teaching Research. v. 4, n 3, pp. 251-274.

. (1998). Interaction and second language learning: two adolescent french immersion students working together. The Modern Language Journal. v. $82, \mathrm{n}^{\circ} 3$, pp. 320-337.

TARONE, E. (1981). Some thoughts on the notion of communication strategy. Tesol Quarterly. v. 15, n¹, pp. 285-295.

VILLAMIL, O.S.; de GUERRERO, M.C.M. (1996). Peer revision in the L2 classroom: social-cognitive activities, mediating strategies, and aspects of social behaviour. Journal of Second Language Writing. v. 5, $\mathrm{n}^{\circ} 1$, pp. 51-75.

VAN LIER, L. (1988). The classroom and the language learner. London: Longman.

VÁRADI, T. (1980). Strategies of target language learner communication: message adjustment. International Review of Applied Linguistics. v. 18, ${ }^{\circ} 1$, pp. 59-71.

VION, R. (1992). La communication verbale. Analyse des interactions. Paris: Hachette. 
Tabela $1^{21}$

\begin{tabular}{|c|c|c|}
\hline & $\begin{array}{l}\text { Tipos de mecanismos de } \\
\text { solução de problemas ou EC }\end{array}$ & \multirow[t]{2}{*}{ Descrição } \\
\hline Insuficiência de recursos & A- MSP Lexicais & \\
\hline & 1. Abandono de mensagem & $\begin{array}{l}\text { O falante deixa a mensagem sem finalizar devido a } \\
\text { limitações de linguagem }\end{array}$ \\
\hline & 2. Redução de mensagem & $\begin{array}{l}\text { O falante decide evitar certas estruturas linguísticas } \\
\text { que são problemáticas para ele }\end{array}$ \\
\hline & 3. Substituição de mensagem & $\begin{array}{l}\text { O falante substitui a mensagem original por uma } \\
\text { nova mensagem }\end{array}$ \\
\hline & 4. Substituição de termos & \\
\hline & 4.1 Mudança de código & Inserção de palavras de L1 na fala em L2 \\
\hline & 4.2 Aproximação & $\begin{array}{l}\text { Uso aproximado de um termo, em lugar do } \\
\text { pretendido. Por exemplo, flor por rosa }\end{array}$ \\
\hline & $\begin{array}{l}\text { 4.3 Palavras-coringa } \\
\text { [all-purpose-words] }\end{array}$ & $\begin{array}{l}\text { Uso de termos mais amplos. Por exemplo: coisa, } \\
\text { fazer }\end{array}$ \\
\hline & 4.4 Omissão completa & $\begin{array}{l}\text { O falante deixa vazio o espaço para o item } \\
\text { problemático }\end{array}$ \\
\hline & $\begin{array}{l}\text { 5. Estratégia de substituição } \\
\text { adicional }\end{array}$ & \\
\hline & 5.1 Estrangeirização & $\begin{array}{l}\text { O falante usa uma palavra de L1 para criar uma } \\
\text { nova palavra de L2 }\end{array}$ \\
\hline & $\begin{array}{l}\text { 5.2 Criação gramatical de } \\
\text { palavra }\end{array}$ & $\begin{array}{l}\text { O falante aplica regras de L2 para criar uma palavra } \\
\text { não-existente em L2. Por exemplo, usa -ed para } \\
\text { verbos irregulares do inglês }\end{array}$ \\
\hline & 5.3 Tradução literal & $\begin{array}{l}\text { O falante traduz literalmente um item de L1 para } \\
\text { L2 }\end{array}$ \\
\hline & 6. Reconceituação & \\
\hline & 6.1 Circunlocução & $\begin{array}{l}\text { O falante dá exemplos, descreve ou ilustra o item } \\
\text { lexical problemático }\end{array}$ \\
\hline & 6.2 Criação semântica de palavra & $\begin{array}{l}\text { Criação de uma palavra não existente em L2, } \\
\text { usando radicais semânticos existentes }\end{array}$ \\
\hline & 6.3 Reestruturação & $\begin{array}{l}\text { O falante desiste da execução do enunciado } \\
\text { específico }\end{array}$ \\
\hline & 7. Pedidos de ajuda & \\
\hline & 7.1 Pedido direto & Perguntas explícitas pedindo ajuda do falante \\
\hline & 7.2 Pedido indireto & $\begin{array}{l}\text { Implicitamente expressa para o interlocutor falta de } \\
\text { conhecimento ou problemas de linguagem }\end{array}$ \\
\hline & B - MSP Gramaticais & \\
\hline & 1. Substituição & \\
\hline & 1.1 Sobregeneralização & $\begin{array}{l}\text { Uso de regras de L2 para construir uma palavra não } \\
\text { existente em L2 }\end{array}$ \\
\hline & 1.2 Transferência & $\begin{array}{l}\text { Uso de regras de L1 para criar um item lexical não } \\
\text { existente em L2 }\end{array}$ \\
\hline & 2. Redução & $\begin{array}{l}\text { O falante usa uma gramática simplificada confiando } \\
\text { que o interlocutor será capaz de presumir o } \\
\text { significado a partir do contexto }\end{array}$ \\
\hline
\end{tabular}

\section{A tradução do inglês é nossa.}




\begin{tabular}{|c|c|c|}
\hline & $\begin{array}{l}\text { C - MSP Fonológicos e } \\
\text { Articulatórios }\end{array}$ & \\
\hline & 1. Recuperação & $\begin{array}{l}\text { O falante se mantém dizendo formas incompletas } \\
\text { ou incorretas até alcançar a melhor opção. Por } \\
\text { exemplo, o fenômeno da "ponta da língua" }\end{array}$ \\
\hline & 2. Substituição & $\begin{array}{l}\text { O falante usa uma palavra com som similar para } \\
\text { compensar o item problemático }\end{array}$ \\
\hline & 3. Redução & $\begin{array}{l}\text { O falante se mantém resmungando uma palavra de } \\
\text { cuja pronúncia não tem certeza }\end{array}$ \\
\hline Pressão de Tempo & $\begin{array}{l}\text { 1. Redução ou abandono da } \\
\text { mensagem }\end{array}$ & $\begin{array}{l}\text { O falante evita estruturas problemáticas ou desiste } \\
\text { da mensagem como um todo }\end{array}$ \\
\hline & $\begin{array}{l}\text { 2. Estratégias relacionadas à } \\
\text { insuficiência de recursos }\end{array}$ & \\
\hline & $\begin{array}{l}\text { 3. Mecanismos de } \\
\text { desaceleração }\end{array}$ & Mecanismos para ganhar tempo \\
\hline & 3.1 Pausas & \\
\hline & 3.1.1 Não-lexicalizadas & \\
\hline & 3.1.1.1 Não-preenchidas & $\begin{array}{l}\text { O falante permanece silencioso por um período de } \\
\text { tempo }\end{array}$ \\
\hline & 3.1.1.2 "Umming and erring" & Uso de $e r, u b, u b m$ \\
\hline & 3.1.2 Prolongamento de som & $\begin{array}{l}\text { O falante decide prolongar uma cadeia sonora para } \\
\text { ganhar tempo enquanto planeja outro enunciado }\end{array}$ \\
\hline & 3.1.3 Pausas lexicalizadas & $\begin{array}{l}\text { Uso de expressões convencionais. Por exemplo: } \\
\text { bem, aí, então }\end{array}$ \\
\hline & 3.2 Repetições & \\
\hline & 3.2.1 Autorrepetições & $\begin{array}{l}\text { O falante repete a palavra ou cadeia de palavras que } \\
\text { acabou de dizer }\end{array}$ \\
\hline & 3.2.2 Repetição albeia & $\begin{array}{l}\text { O falante repete algo que o interlocutor acabou de } \\
\text { dizer }\end{array}$ \\
\hline $\begin{array}{l}\text { Deficiências percebidas na } \\
\text { produção linguística própria }\end{array}$ & 1. Autocorreções ou reparos & \\
\hline & 1.1 Reparo de erro & Correção de lapsos na produção do falante \\
\hline & 1.2 Reparo de adequação & Correção de informação inapropriada \\
\hline & 1.3 Reparo diferente & $\begin{array}{l}\text { O falante muda o plano de fala e fornece nova } \\
\text { informação }\end{array}$ \\
\hline & 1.4 Reparo de refraseamento & $\begin{array}{l}\text { O falante parafraseia um enunciado particular } \\
\text { porque não tem certeza sobre sua exatidão }\end{array}$ \\
\hline & 2. Perguntas de verificação & \\
\hline & 2.1 Verificação de compreensão & $\begin{array}{l}\text { O falante faz perguntas para se assegurar de que o } \\
\text { interlocutor entendeu a mensagem }\end{array}$ \\
\hline & 2.2 Verificação da própria exatidão & $\begin{array}{l}\text { Repetição de palavras com entonação interrogativa } \\
\text { para checar se o que foi dito está correto }\end{array}$ \\
\hline
\end{tabular}




\begin{tabular}{|l|l|l|}
\hline $\begin{array}{l}\text { Deficiências percebidas no } \\
\text { desempenho do interlocutor }\end{array}$ & 1. Pedido de repetição & $\begin{array}{l}\text { O falante pede que o interlocutor repita porque } \\
\text { não conseguiu entender ou escutar o que foi dito }\end{array}$ \\
\hline \multirow{7}{*}{ 2. Pedido de esclarecimento } & $\begin{array}{l}\text { O falante pede explicação de estruturas linguísticas } \\
\text { não-familiares }\end{array}$ \\
\cline { 2 - 3 } & 3. Expressão de incompreensão & Por exemplo: Não sei o que é isto! \\
\cline { 2 - 3 } & 5. Pedido de confirmação & $\begin{array}{l}\text { Perguntar algo ao interlocutor para confirmar o que } \\
\text { foi dito }\end{array}$ \\
\cline { 2 - 3 } & $\begin{array}{l}\text { Resumir o que o interlocutor disse para verificar se } \\
\text { entendeu adequadamente }\end{array}$ \\
\cline { 2 - 4 } & $\begin{array}{l}\text { O falante tenta presumir a mensagem do } \\
\text { interlocutor. Esta estratégia é aplicada quando o } \\
\text { falante realmente não conseguiu captar nada da } \\
\text { mensagem }\end{array}$ \\
\hline & 7. Reparo do outro & $\begin{array}{l}\text { O falante corrige algo na fala do interlocutor } \\
\text { para manter o fluxo da conversação }\end{array}$ \\
\cline { 2 - 3 } & 8. Fingir compreensão & \\
\hline
\end{tabular}

Recebido: 19/02/2012

Aceito: 15/06/2012 
